\title{
Lipase Catalyzed Methanolysis of Tri-(12-Hydroxy Stearoyl)-Glycerol in Organic Solvents
}

\author{
Sung-Tae Kang1, Thomas A. McKeon ${ }^{2 *}$ \\ ${ }^{1}$ Seoul National University of Science and Technology, Seoul, South Korea \\ ${ }^{2}$ United States Department of Agriculture, Agricultural Research Service, Western Regional Research Center, Albany, CA, USA \\ Email: *thomas.mckeon@ars.usda.gov
}

How to cite this paper: Kang, S.-T. and McKeon, T.A. (2016) Lipase Catalyzed Methanolysis of Tri-(12-Hydroxy Stearoyl)Glycerol in Organic Solvents. Advances in Enzyme Research, 4, 152-157. http://dx.doi.org/10.4236/aer.2016.44014

Received: October 1, 2016

Accepted: December 25, 2016

Published: December 28, 2016

Copyright (c) 2016 by authors and Scientific Research Publishing Inc. This work is licensed under the Creative Commons Attribution International License (CC BY 4.0). http://creativecommons.org/licenses/by/4.0/

\begin{abstract}
Castor oil is the source of numerous products and is the only commercial source of the fatty acid ricinoleate, 12-hydroxy-oleate. Hydrogenated castor oil is similarly useful as the source of 12-hydroxy-stearic acid, best known as a component of lithium grease. Mono- and diacylglycerols are derived from castor oil and are useful in development of lubricants and emulsifiers for cosmetics, pharmaceutical and food use. Acylglycerols derived from hydrogenated castor oil may be similarly useful, albeit with different physical and chemical properties. We have evaluated the use of immobilized lipases to generate acylglycerols, using organic solvents to modulate the action of lipase to produce mono- and diacylglycerols, using tri-(12-hydroxy stearoyl)-glycerol as a model for hydrogenated castor oil. The presence of an alkylated oxygen in the solvent appears to be an important factor in supporting lipase activity, with diisopropyl ether providing the best yield of di-(12-hydroxy stearoyl)-glycerol.
\end{abstract}

\section{Keywords}

Castor Oil, Enzyme, Lipase, Diacylglycerol, Monoacylglycerol

\section{Introduction}

Castor oil is unique among commodity seed oils as it contains up to $90 \%$ ricinoleate (12-hydroxy-octadec-cis9-enoate). The presence of the mid-chain hydroxyl group imparts physical and chemical functionality making castor oil uniquely useful as a chemical and industrial feedstock. Castor oil forms the basis for emulsifiers used in food, cosmetic and pharmaceutical preparations. Acylglycerols and free fatty acids derived from hydrogenated castor oil contain 12-hydroxy stearate, and these products are similarly useful as emulsifiers. The lithium salt of 12-hydroxy stearate is used in formulating 
the well-known lubricant lithium grease which is very useful for reducing metal-onmetal friction. The hydroxyl and carboxyl groups interact with metal and the non-polar hydrocarbon backbones help to retain non-polar additives. Similar to ricinoleate, the hydroxyl-stearate is also used as an emulsifier in cosmetics and adds beneficial antimicrobial activity to help maintain product stability [1].

We have previously demonstrated the utility of lipases for extraction from seed and simultaneous transmethylation using supercritical $\mathrm{CO}_{2}$ extraction with methanol as a co-solvent on a bed of immobilized lipase [2]. Additionally, by judicious use of solvent and lipase, we have been able to produce high yields of 1,2-diricinoleoyl diacylglycerol [3]. The 1,2-diricinoleoyl DG was especially useful in identifying the activity of the diacylglycerol acyltransferase from castor seed [4]. By varying the amount of hydroxyl fatty acid substitution on glycerol, in addition to their use as emulsifiers and viscosity modulators, we believe these products may also be of value in developing polyurethanes and composites with differing functional properties resulting from the differences in acyl-substitution on glycerol [1].

\section{Materials and Methods}

\subsection{Materials}

Solvents were purchased: HPLC-grade methanol, n-butanol, acetonitrile, acetone, ethyl acetate, chloroform, hexane and toluene from Fisher Scientific (Fairlawn, NJ); DIPE from FlukaChemie (Buchs, Switzerland); iso-octane from Sigma-Aldrich (St. Louis, $\mathrm{MO}$ ) and ethanol from Acros Organics (Fairlawn, NJ). Lithium chloride, magnesium nitrate, sodium chloride and anhydrous sodium sulfate were obtained from J.T. Baker Inc. (Phillipsburg, NJ). Potassium sulfate, sodium phosphate, and disodium phosphate were purchased from Spectrum Chemical Mfg. Corp. (Gardena, CA). The lipase R (P. roquefortii, PRL) was the kind gift from Amano Enzymes Inc. (Nagoya, Japan) and Lipozyme RMIM 60 from Rhizomucor miehei was generously supplied by Novozymes North America (Franklinton, NC).

THS-glycerol is not commercially available and was prepared by lipase-catalyzed esterification. Reactions were carried out by mixing $40.8 \mathrm{mg}$ of glycerol adsorbed on silica gel $(1: 1, w / w)$ and $0.2 \mathrm{~g}$ of the 12-hydroxystearic acid (12-HSA) for a molar ratio of FFA to GL of 3:1. The reaction was performed at $85^{\circ} \mathrm{C}$, just above the melting temperature of 12-HAS. At this temperature no organic solvent is necessary to solubilize the substrates, which allows for the use of a reaction medium solely composed of the necessary substrates. The optimal conditions for synthesis of THS-glycerol were a molar ratio of the HS to adsorbed GL was 3:1, lipase RMIM loading was 10\% (w/w) of the weight of HS, $A_{w}$ for all components was adjusted to 0.11 by equilibration in a desiccator containing saturated $\mathrm{LiCl}[5]$, and the reaction temperature was $85^{\circ} \mathrm{C}$. The reaction mixture in an open glass vial $(17 \mathrm{~mm}$ i.d. $\times 85 \mathrm{~mm} \mathrm{~L})$ was mixed vigorously by a magnetic stirrer $(150 \mathrm{rpm})$ at the equilibrated temperature of $85^{\circ} \mathrm{C}$. During incubation at different times, two $40 \mu \mathrm{l}$ samples were withdrawn from each flask and mixed with $0.4 \mathrm{ml}$ of 2-propanol and stored in a freezer at $-20^{\circ} \mathrm{C}$ for later HPLC analysis. 


\subsection{HPLC Analysis}

The course of esterification was monitored by reverse phase HPLC as previously described [3]. The expected products of lipase reaction, i.e., HS, MHS-glycerol, DHSglycerol and THS-glycerol were analyzed by injection of $50 \mu \mathrm{L}$ of sample on a $\mathrm{C}_{18} \mathrm{RP}$ HPLC column, using mobile phase of methanol (A) and methanol: water (90:10) (B). The gradient was from $100 \% \mathrm{~B}$ to $100 \% \mathrm{~A}$ in $20 \mathrm{~min}$, then held for $12 \mathrm{~min}$, with a reverse gradient to $100 \% \mathrm{~B}$ in $2 \mathrm{~min}$, and equilibration with B for $6 \mathrm{~min}$. The total run time was $40 \mathrm{~min}$. The flow rate was $1.0 \mathrm{~mL} / \mathrm{min}$., and detection was performed at 205 $\mathrm{nm}$. Results are expressed as percentage of peak areas. Retention times for MHSglycerol, HS, DHS-glycerol and THS-glycerol were $4.94 \mathrm{~min}, 7.52 \mathrm{~min}, 20.46 \mathrm{~min}$, and $32.34 \mathrm{~min}$, respectively, and identity of each product confirmed by LC/MS.

Preparation of THS-glycerol for methanolysis reactions was carried out by combining the product from multiple reactions and isolating the THS-glycerol by preparative HPLC using a $250 \times 15 \mathrm{~mm}$ Phenomenex Luna $\mathrm{C}_{18} \mathrm{RP}$ column, 5 micron particle size, from Phenomenex, (Torrance, CA) eluted according to Turner et al. [3].

\subsection{Methanolysis Reaction}

General reaction conditions used were $100 \mathrm{mg}$ of THS-glycerol (110micromole) dissolved in $5 \mathrm{ml}$ of reaction media and $0.625 \mathrm{ml}(1.54 \mathrm{mmole})$ of methanol was mixed with $100 \mathrm{mg}$ of free enzyme. The lipase PRL, reaction media, methanol and glassware were allowed to equilibrate for at least $48 \mathrm{~h}$ in desiccators containing a saturated aqueous solution of $\mathrm{MgNO}_{3}$ to reach $\mathrm{A}_{\mathrm{w}}$ of 0.53 [5]. The reaction took place in closed glass tubes at $25^{\circ} \mathrm{C}$ and shaking at $220 \mathrm{rpm}$. Fractions of 100 microliter were taken out at pre-determined time intervals, the solvent was removed by nitrogen, $0.5 \mathrm{~mL}$ of 2 propanol was added to the residue and samples were stored briefly at $-20^{\circ} \mathrm{C}$ and analyzed by HPLC. The reactions were performed in duplicate.

\section{Results and Discussion}

Figure 1 displays the results of the esterification reaction of HS with glycerol as catalyzed by lipase RMIM. The reaction presented provided conditions needed to obtain a good yield of THS-glycerol and was not monitored closely following determination that, after a 1-day incubation, up to $80 \%$ of the product is THS. As an alternative to this lipase-catalyzed reaction, it is also possible to hydrogenate castor oil and isolate the THS-glycerol product by preparative HPLC as described in Materials and Methods.

The results of the methanolysis reaction (Table 1) show no clear connection with hydrophobicity of the solvent. Organic solvents provide a very useful medium for lipase-mediated action, as both substrate and product are hydrophobic and soluble in organic solvents [6] [7]. In general, enzyme reactions are considerably slower in organic solvents [8], although this is highly dependent on the substrate [9] with water-insoluble triacylglycerols more readily lysed by the action of lipases.. The Penicillium lipases tend to be less active on diacylglycerol substrates, thus being very useful for generating desired diacylglycerols as intermediates instead of monoacylglycerols or complete hy- 


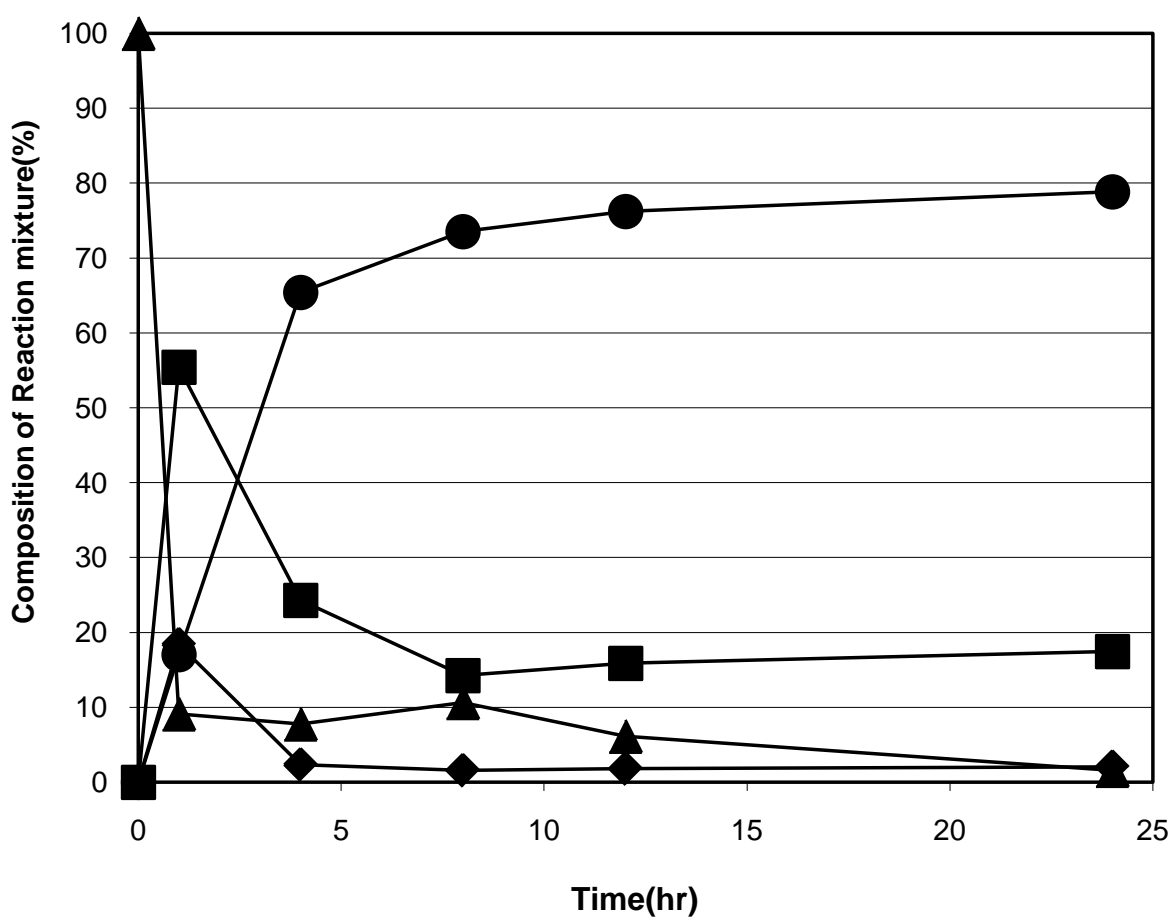

Figure 1. Production of triHS-glycerol by enzymatic esterification of 12-hydroxystearic acid and glycerol at Aw $=0.11$; Reaction conditions were as follows: $40.8 \mathrm{mg}$ of GL adsorbed on silica gel (weight ratio of glycerol to adsorbent $=1: 1$ ), $0.2 \mathrm{~g}$ of 12-hydroxystearic acid, molar ratio of FFA to glycerol of 3:1, $20 \mathrm{mg}$ of RMIM (Aw 0.11), stirred at $150 \mathrm{rpm}$ and $85^{\circ} \mathrm{C}$. MHS-glycerol ( $\bullet$ ); HS ( $\boldsymbol{\Delta})$; DHS-glycerol (•); and THS-glycerol $(\bullet)$.

Table 1. Effect of solvent on acyl-glycerol products from of tri-(12-hydroxy-stearate)-glycerol.

\begin{tabular}{cccccc}
\hline Solvents & Log P* & MHS-glycerol & DHS-glycerol & THS-glycerol $\begin{array}{c}\text { \% Conversion to MHS- and } \\
\text { DHS-glycerols }\end{array}$ \\
\hline Acetonitrile & -0.34 & 2.0 & 24.4 & 59.6 & 31 \\
Ethanol & -0.31 & 12.2 & 33.1 & 39.2 & 54 \\
Acetone & -0.24 & 2.2 & 18.0 & 64.4 & 24 \\
Ethyl acetate & 0.73 & 2.2 & 17.4 & 65.3 & 23 \\
1-Butanol & 0.88 & 10.0 & 32.7 & 42.5 & 50 \\
Diisopropyl ether & 1.52 & 6.2 & 52.0 & 22.2 & 72 \\
Chloroform & 1.97 & 2.0 & 12.5 & 69.3 & 17 \\
Toluene & 2.73 & 7.5 & 28.6 & 48.0 & 43 \\
Hexane & 4.0 & 2.1 & 2.2 & 85.4 & 5 \\
Isooctane & 4.5 & 4.1 & 2.6 & 70.0 & 9 \\
\hline
\end{tabular}

${ }^{\star}$ From Sangster [6] except isooctane, from Kumar and Gross [7].

drolysis. In our results presented in Table 1, we see primarily an accumulation of diacylglycerols (DHS) in organic solvents with the exception of the two alcohols.

Gagnon and Vasudevan [10] observed a good correlation of lipase-catalyzed methanolysis of soybean oil with increasing hydrophobicity of the solvent used. Our results differ, but this is probably due to our use of a different lipase, PRL, different reaction 
conditions and the unusual hydroxyl fatty acid. The higher levels of methanolysis are observed in the ether DIPE and the two alcohols, ethanol and butanol. Of course, the latter two solvents may also participate in the alcoholysis reaction and, aside from the acylglycerols, we did not attempt to quanify the levels of the fatty acid esters formed from the alcohol solvents. Similar results were observed, also using immobilized PRL to generate diacylglycerols from tricaprin, trilaurin and tripalmitin [9]. Methanolysis in toluene was similar in yield to the two alcohols and DIPE proved to be the best solvent for controlled methanolysis of THS with a yield of 73\% MHS and DHS, and 65\% DHS.

Generally, carefully controlled reactions require maintenance of stable water activity, as enzymes vary on their reactivity and stability in organic solvents as a result of the presence of water. Water will affect the structure of the enzyme and excessive water produced during hydrolysis can interfere with methanolysis as a result of the competing hydrolytic reaction [11].

\section{Conclusion}

Our results suggest that careful use of lipase in DIPE can provide suitable yields of DHS for use in emulsifiers for cosmetics, pharmaceuticals and food as well as viscosity modifiers in lubricants. The presence of two fatty acid hydroxyl groups and an available hydroxyl on the glycerol backbone provide the possibility of using these 12-hydroxy stearioyl diacylglycerols for developing polyurethanes with novel properties.

\section{References}

[1] McKeon, T.A. (2016) Castor (Ricinuscommunis L.) In: McKeon, T.A., Hayes, D.G., Hildebrand, D.F. and Weselake, R.J., Eds., Industrial Oil Crops, Academic Press, Amsterdam and AOCS Press, Champaign-Urbana, 75-112.

[2] Turner, C., Whitehand, L.C., Nguyen, T. and McKeon, T. (2004) Optimization of a Supercritical Fluid Extraction/Reaction Methodology for the Analysis of Castoroil Using Experimental Design. Journal of Agricultural and Food Chemistry, 52, 26-32. https://doi.org/10.1021/jf0347665

[3] Turner, C., He, X., Nguyen, T., Lin, J.T., Wong, R.Y., Lundin, R.E., Harden, L. and McKeon, T. (2003) Lipase Catalyzed Methanolysis of Triricinolein in Organic Solvent to Produce 1,2(2,3)-diricinolein. Lipids, 38, 1197-1206.

https://doi.org/10.1007/s11745-003-1179-5

[4] He, X., Turner, C., Chen, G., Lin, J.-T. and McKeon, T.A. (2004) Cloning and Characterization of a cDNA Encoding Diacylglycerol Acyltransferase from Castor Bean. Lipids, 39, 311318. https://doi.org/10.1007/s11745-004-1234-2

[5] Halling, P.J. (1992) Salt Hydrates for Water Activity Control with Biocatalysis in Organic Media. Biotechnology Techniques, 6, 271-276. https://doi.org/10.1007/BF02439357

[6] Sangster, J. (1989) Octanol-Water Partition Coefficients of Simple Organic Compounds. Journal of Physical Chemistry Reference Data, 18, 1111-1228. https://doi.org/10.1063/1.555833

[7] Kumar, A. and Gross, R.A. (2000) Candida antartica Lipase B Catalyzed Polycaprolactone Synthesis: Effects of Organic Media and Temperature. Biomacromolecules, 1, 133-138. https://doi.org/10.1021/bm990510p 
[8] Klibanov, A.M. (2001) Improving Enzymes by Using Them in Organic Solvents. Nature, 409, 241-246. https://doi.org/10.1038/35051719

[9] Fureby, A.M., Tian, L., Adlercreutz, P. and Mattiasson, B. (1997) Preparation of Diglycerides by Lipase-Catalyzed Alcoholysis of Triglycerides. Enzyme and Microbial Technology, 20, 198-206. https://doi.org/10.1016/S0141-0229(96)00133-0

[10] Gagnon, M.D. and Vasudevan, P.T. (2011) Effects of Solvent and Enzyme Source on Transesterification Activity. Energy \& Fuels, 25, 4669-4674. https://doi.org/10.1021/ef2008776

[11] Sankaran, R., Show, P.L. and Chang, J.-S. (2016) Biodiesel Production Using Immobilized Lipase: Feasibility and Challenges. Biofuels, Bioproducts \& Biorefining, 10, 896-916. https://doi.org/10.1002/bbb.1719

\section{Abbreviations}

HS: 12-Hydroxystearate

DIPE: Diisopropyl Ether

MHS-glycerol: Mono-(12-hydroxy stearoyl)-glycerol

DHS-glycerol: Di-(12-hydroxy stearoyl)-glycerol

THS-glycerol: Tri-(12-hydroxy stearoyl)-glycerol

RP: Reverse-phase

Submit or recommend next manuscript to SCIRP and we will provide best service for you:

Accepting pre-submission inquiries through Email, Facebook, LinkedIn, Twitter, etc.

A wide selection of journals (inclusive of 9 subjects, more than 200 journals)

Providing 24-hour high-quality service

User-friendly online submission system

Fair and swift peer-review system

Efficient typesetting and proofreading procedure

Display of the result of downloads and visits, as well as the number of cited articles

Maximum dissemination of your research work

Submit your manuscript at: http://papersubmission.scirp.org/

Or contact aer@scirp.org 